\title{
João Claudio Todorov: Planejador de Contingências para o Aprender a Aprender e para o Aprender a Ensinar
}

\author{
Rachel Nunes da Cunha \\ Universidade de Brasília
}

\section{João Claudio Todorov: Contingencies Programmer to Learn How to Learn and Teach}

Ao receber o honroso convite da Editora de Psicologia: Teoria e Pesquisa para apresentar João Claudio Todorov para esta edição especial, recorri a uma apresentação oral que fiz por ocasião da homenagem que a Sociedade Brasileira de Psicologia (SBP) conferiu ao professor Todorov, como parte da comemoração dos 30 anos da SBP. Confesso que a tarefa de hoje é tão difícil quanto fora na noite de abertura da XXX Reunião Anual da SBP, em outubro de 2000, em Brasília. A dificuldade está na responsabilidade de fazer uma breve apresentação do professor, do pesquisador e do orientador, com imensa contribuição nessas atividades acadêmicas, que também teve e continua tendo um papel importante em atividades políticas e administrativas que têm como foco a universidade, a própria Psicologia e a ciência no País. Nesta edição especial de Psicologia: Teoria e Pesquisa, o professor João Claudio Todorov é homenageado pelo Instituto de Psicologia (IP), ao lado de colegas que construíram e ainda constroem a Psicologia da Universidade de Brasília (UnB) e no Brasil, com impacto internacional.

A melhor forma que encontrei para apresentar João Claudio é a partir das minhas impressões registradas ao longo de 24 anos de convivência, primeiramente como candidata a aprendiz da Análise do Comportamento, depois como aluna de Mestrado e, finalmente, com muita honra, sua colega de departamento. Essas impressões levaram-me a descrevê-lo como planejador de contingências para o aprender a aprender e para o aprender a ensinar.

O primeiro vínculo de João Claudio com o IP ocorreu no período de 1964 a 1965, como instrutor e aluno do programa de pós-graduação (Mestrado). Como instrutor João Claudio teve atribuições antes mesmo da instalação do departamento e da vinda da equipe para Brasília. Essas atribuições abrangeram a preparação das primeiras disciplinas, incluindo traduções de textos, por exemplo, Ciência e Comportamento Humano, de B. F. Skinner, tradução feita em parceria com Rodolpho Azzi (da Cunha, 2004; Todorov, 1997). João Claudio graduou-se em Bacharelado e Licenciatura em Psicologia, em 1962 e 1963, respectivamente, na Universidade de São Paulo (USP). Doutorou-se em Psicologia, em 1969, na Arizona State University, sob a orientação de Stanley S. Pliskoff, com tese intitulada "Some effects of punishment on concurrent performances".

Nos Estados Unidos, João Claudio teve experiências acadêmicas como Teaching Assistant, na Arizona State University, Research Assistant, no Institute for Behavioral Research e Assistant Professor, na University of Virginia. Ao regressar ao Brasil, foi Professor Assistente Doutor da Universidade de São Paulo, Campus de Ribeirão Preto, no período de 1969 a 1975. No México, Todorov esteve como Professor Visitante na Universidad Nacional Autónoma. Todorov retornou aos Estados Unidos na década de 1990 como Professor Visitante na State University of New York at Stony Brook.

Em 1975, Todorov retornou a Universidade de Brasília, na qual se aposentou como Professor Titular, mas deu continuidade às atividades de orientação como Pesquisador Associado do Departamento de Processos Psicológicos Básicos. Atualmente, é Professor Titular da Universidade Católica de Goiás, atuante na pós-graduação; é Coordenador do curso de Psicologia, do Instituto de Educação Superior de Brasília (IESB), curso planejado por ele; é Consultor do Centro de Gestão e Estudos Estratégicos e é membro do Conselho Diretor da Fundação Universidade de Brasília (FUB).

Concomitante à carreira acadêmica, João Claudio exerceu várias atividades administrativas na UnB, tais como: Chefe de Departamento, Membro da Comissão de Avaliação da UnB, Direção do Centro de Excelência em Turismo, Decano de Pesquisa e Pós-graduação, Vice-reitor e Reitor. O interesse político de Todorov e a luta pela redemocratização da UnB fez com que ele se engajasse no Movimento Docente e fosse um dos fundadores da Associação de Docentes da UnB (ADUnB), tornando-se Presidente no biênio 1978-1980. Hoje a ADUnB é uma Seção Sindical do ANDES - Sindicato Nacional.

Falar sobre João Claudio é falar sobre sua missão com a formação de pesquisadores e de professores que pode ser evidenciada por seus orientados que hoje são lideranças em vários programas de pós-graduação, em grupos de pesquisas e em diversas universidades brasileiras, que contribuem para o desenvolvimento e para a divulgação da Psicologia e da Análise do Comportamento no País. Ao longo da carreira acadêmica de João Cláudio se verifica sua contribuição direta e profícua para a Psicologia como ciência explicitada nas diversas publicações e nas colaborações como Editor de revistas científicas, por exemplo, Ciência e Profissão, editada pelo Conselho Federal de Psicologia; Psicologia: Teoria e Pesquisa, editada pelo IP da UnB e Análise do Comportamento, editada pelo Instituto Brasiliense de Análise do Comportamento. João Cláudio também tem contribuições como membro de Conselhos Editoriais de revistas tais como: Behavior and Philosophy, Journal of the Experimental Analysis of Behavior e Revista Mexicana de la Conducta. 
Durante esses anos de docência, a idéia norteadora da orientação de Todorov tem sido o laboratório de Análise Experimental do Comportamento como fundamento da formação de pesquisador, no qual o rigor do método e os princípios do fazer ciência e da Psicologia, especificamente, da Análise do Comportamento são estudados e ensinados. $\mathrm{Na}$ sua maestria em arranjar contingências, Todorov modelou o comportamento de pesquisador de muitos jovens e a maioria desses jovens fez o mestrado sob a sua supervisão, tendo no Mestre, o apoio para cursar o doutorado no exterior quando ainda no Brasil não havia muitos programas de doutorado; entretanto, ele orientou vários estudantes de doutorado no País e continua supervisionando dissertações e teses de mestrado e doutorado, respectivamente.

É importante destacar que a atividade em tempo integral deste eminente professor e pesquisador, mesmo quando ocupava cargos administrativos de diferentes envergaduras, se alimentava e era alimentada por ações além do ensinar, do treinar e do pesquisar. João Claudio se dedicou e tem se dedicado a instituições importantes para o desenvolvimento do conhecimento científico e tecnológico, da Psicologia, e em especial da Análise do Comportamento, por exemplo, Sociedade Brasileira para o Progresso da Ciência, Sociedade Brasileira de Psicologia e Conselho Nacional de Desenvolvimento Científico e Tecnológico (CNPq).

Falar sobre João Claudio é falar sobre o Mestre que nos legou lições sobre como planejar contingências para o aprender a aprender e o aprender a ensinar que identifico em três artigos didáticos que os considero uma trilogia fundamental para a iniciação à Análise do Comportamento: 1) Behaviorismo e Análise Experimental do Comportamento (Todorov, 1982); 2) A Psicologia como o estudo de interações (Todorov, 1989) e 3) O conceito de contingência na psicologia experimental (Todorov, 1991).

Em Behaviorismo e Análise Experimental do Comportamento, Todorov se preocupa em esclarecer os termos behaviorismo, Análise Experimental do Comportamento e Psicologia a partir de Skinner (1980) e Harzem e Miles (1978). Todorov elucida o termo behaviorismo com uma citação de Skinner (1980, p. 339): "O comportamentalismo, com acentuação no 'ismo', não é o estudo científico do comportamento, mas uma filosofia da ciência preocupada com o tema e métodos da psicologia" (em Todorov, 1982, p. 10). Também esclarece que a Análise Experimental do Comportamento é uma "maneira de estudar o objeto da Psicologia" e não uma área da Psicologia, ou seja, refere-se ao método de investigação. $\mathrm{Na}$ mesma lógica, Todorov ressalta que a Análise do Comportamento não se restringe a Análise Experimental do Comportamento, ela se origina "de uma posição behaviorista assumida por Skinner por motivos mais históricos que puramente lógicos" (p. 12).

Nosso Mestre recupera um princípio fundamental que pressupõe que o comportamento enquanto um evento natural ocorre de forma ordenada e regulada, assim podemos observar e analisar, sistematicamente, as circunstâncias de ocorrência do comportamento humano e predizer como os indivíduos comportar-se-ão em circunstâncias similares. É a crença nesse princípio que nos possibilita o estudo científico do comportamento e como costuma dizer Todorov: onde há alguém se comportando haverá um lugar para o psicólogo.

Nesse artigo, Todorov explica o programa de Skinner para a construção da ciência do comportamento, descrito em "Ciência e Comportamento Humano", para o qual Skinner teve na Análise Experimental do Comportamento um dos aspectos de empreendimento maior para sua proposta do estudo do comportamento dos organismos.

No segundo artigo desta trilogia, A Psicologia como o Estudo de Interações, Todorov caracteriza a Psicologia na perspectiva analítico-comportamental como o estudo de interações organismo-ambiente. Nessa perspectiva é enfatizado que a Psicologia estuda relações funcionais; portanto, o comportamento é estudado e compreendido como processo e, continuamente, o organismo interage no meio ambiente, modificando-o e o comportamento do organismo é modificado pelas conseqüências dessa interação. Assim "as interações organismo-ambiente são tais que podem ser vistas como um continuum onde a passagem da psicologia para biologia ou para as ciências sociais é muitas vezes questão de convencionar-se limites ou de não se preocupar muito com eles" (Todorov, 1989, p. 348).

Outro fundamento enfatizado é a concepção darwiniana de homem que o vê como parte da natureza; portanto, o comportamento humano ou de qualquer organismo não-humano é um evento natural que pode ser estudado à luz das ciências naturais. A visão darwiniana

da natureza humana nem é nova, nem é exclusivamente da psicologia ou do comportamentalismo. O que torna a moderna análise do comportamento distinta é seu uso e a exploração das possibilidades que a visão oferece para o estudo de interações organismo-ambiente (p. 349).

Neste arranjo didático de A Psicologia como o Estudo de Interações, Todorov apresenta uma síntese da decomposição das interações organismo-ambiente que se caracteriza em ambiente externo, que é dividido em físico e social, e em ambiente interno, que é dividido em biológico e histórico. Essas subclasses de interações têm historicamente caracterizado áreas da Psicologia e Todorov explicita que

a decomposição do conceito de ambiente em externo, físico ou social, e interno, biológico ou histórico, é apenas um recurso de análise útil para entender-se a fragmentação da psicologia em diversos campos, e para os diversos fatores que, indissociáveis, participam das interações estudadas pelos psicólogos (p. 352).

Outro fundamento desse artigo didático é que os conceitos de contingências e de relações funcionais são utilizados como instrumento para o estudo de interações organismoambiente. Assim, o

experimentador manipula contingências em busca de relações funcionais e das condições (variáveis de contexto) nas quais podem ser observadas. Um sistema de relações funcionais constituirá uma teoria útil se vier acompanhado de especificações 
de onde e quando, no ambiente externo, as variáveis de contexto devem ser encontradas (p. 355).

O terceiro artigo que elegi para compor o que estou caracterizando como uma trilogia para iniciar alguém na Análise do Comportamento é O conceito de Contingência na Psicologia Experimental. A dificuldade desse conceito não se dá apenas na sua conceituação e descrição, mas também como um instrumento de análise para o estudo de relações funcionais entre o organismo e o ambiente. Todorov explana que há uma diversidade de procedimentos experimentais que o conceito de contingência viabiliza para investigar desde relações funcionais respondentes, por exemplo, os reflexos condicionais de Pavlov, às relações funcionais operantes, por exemplo, a quantificação da Lei do Efeito.

O conceito de contingência é definido como uma relação entre eventos ambientais (SS) ou entre comportamento e eventos ambientais (RS) que é descrita na forma condicional “se..., então...". O pesquisador analista do comportamento utiliza-se de contingências e as modifica como sua principal variável de estudo, ou seja, como variável independente. $\mathrm{O}$ termo contingência é empregado por analistas do comportamento para se referir às regras que especificam relações funcionais do tipo SS ou RS

Para mim a palavra Mestre, que conforme o dicionário eletrônico Houaiss, é a "pessoa dotada de excepcional saber, competência, talento em qualquer ciência ou arte", é a melhor forma para definir João Cláudio Todorov e, em linguagem menos coloquial, eu o defino como "Planejador de contingências para o aprender a aprender e para o aprender a ensinar". João Cláudio Todorov continua nos brindando com sua importante contribuição à Psicologia e à Análise do Comportamento.

\section{Referências}

da Cunha, R. N. (2004). História da perspectiva behaviorista radical. Em Marina Massimi (Org.). História da psicologia no Brasil do século XX. São Paulo: EPU, pp. 199-216.

Harzem, P. \& Miles, T. R. (1978). Conceptual issues in operant psychology. Chischester: Wiley.

Instituto Antônio Houaiss (2002). Dicionário eletrônico Houaiss da língua portuguesa $1.0,5^{\mathrm{a}}$.

Skinner, B. F. (1980). Contingências do reforço: Uma análise teórica. (R. Moreno, Trad.). Coleção Os Pensadores. São Paulo: Abril Cultural. (Trabalho original publicado em 1969)

Todorov, J. C. (2006). Currículo do Sistema Lattes. Última atualização em 18/09/2006. Acessado em 27/10/2006 em http://buscatextual.cnpq.br/buscatextual/visualizacv. jsp?id=K4783554U5 .

Todorov, J. C. (1991). O conceito de contingências na psicologia experimental. Psicologia: Teoria e Pesquisa, 7(1), 59-70.

Todorov, J. C. (1989). A psicologia como estudo de interações. Psicologia: Teoria e Pesquisa, 5(3), 25-347.

Todorov, J. C. (1982). Behaviorismo e análise experimental do comportamento. Cadernos de Análise do Comportamento, 3, 10-23.

Todorov, M. S. R. (1997). A Psicologia na Universidade de Brasília de 1963 a 1987. Brasília: Editora Universidade de Brasília/CEDOC. 